\title{
Studies on public health and hygiene condition of retailers at fish markets in south-central Bangladesh
}

\author{
M. M. Alam ${ }^{1 *}$, M. M. Haque ${ }^{2}$ and F. H. Shikha ${ }^{1}$ \\ ${ }^{1}$ Department of Fisheries Technology, Bangladesh Agricultural University, Mymensingh-2202 and ${ }^{2}$ Department of \\ Aquaculture, Bangladesh Agricultural University, Mymensingh-2202, Bangladesh, "E-mail: imran01bau@yahoo.com
}

\begin{abstract}
Bangladesh is a fish producing country from the ancient history due to its deltaic nature agro-ecologically. Accordingly fish marketing systems developed in traditional systems sincelong. This study was conducted in two retail fish markets located in Rajbari and Barisal Sadar Upazila in the south central region of Bangladesh focusing public health and hygiene condition of retailers. The questionnaire interview with 30 retailers and participatory rural appraisal (PRA) tools were used to get the information from the retailers and other value chain stakeholders. About $13 \%$ of the retailers had no education, however $60 \%$ had primary level and $27 \%$ had secondary level of education. Although many of them were literate, their knowledge and practice about public health, hygiene and sanitation was found to be very poor. Due to lack of knowledge on public health, they were found to be infected by various contagious diseases such as common cold (cough, coryza etc.), diarrhoea, lesion (lesion on hands, between fingers, on the tip of the fingers, between toes, on the nail and tip of the toes etc.) and skin disease. About $57 \%$ of them were affected with lesion on hands, while 33, 23, 7, 13 and 10\% were affected with lesion between fingers, between toes, on the tip fingers, on the nail and tip of toes and skin disease on legs, respectively.Fish markets operated by them were ill-managed, unhygienic and unscientific. So, the hygiene and sanitation system of retail fish markets were very poor and unhealthy. Market should have adequate water supply, toilets and other sanitation facilities. Due to poor infrastructural facilities in harvest and post-harvest, landing, handling, preservation, distribution, marketing and quality assurance, the fish retailers suffered from serious health problems. Good personal hygiene management is therefore essential for the safe handling and preparation of fish and fisheries products. To ensure this, quick and proper action should be needed by the government, particularly by the local government and rural development (LGRD) authorities.
\end{abstract}

Keywords: Public health, Hygiene, Retailers, Markets

\section{Introduction}

Bangladesh is a riverine country where about 230 rivers spread throughout the country (Rounak and Rahman, 2013). The country is one of the world's leading inland fisheries producer with a production of $28,21,266 \mathrm{MT}$ during 2012-13, with total marine catch of 5,88,988MT and the total production from aquaculture was 18,59,808MT during 2012-13 (DoF, 2014). Initially fish was harvested from the natural water bodies however, over the years due to various changes of environmental and other anthropogenic reasons, it has been declined drastically. To compensate this lacking, aquaculture production has been increasing day by day which became a considerably larger sector than the capture fisheries (DoF, 2014). Whatever the production systems, the fish marketing is still in increasing trend and with growing urbanization, the number of fish markets are increasing dramatically. Unfortunately, the infrastructural improvement of fish market has not been developed yet, thus it creates various problems to the associated stakeholders.

Markets at all levels had retailing arrangements, that was, a group of retailers who sold fish to the consumers. In major cities like Dhaka, Chittagong, Khulna, Rajshahi, Sylhet, and Barisal and in district towns, city corporations or municipalities manage the retail markets. The number of fish markets operated seven days a week has been increasing day by day due to increasing demand of fish. In general, conditions in urban and rural retail markets were not satisfactory in terms of stalls, parking, spacing, sanitation, drainage and management. Fish marketing in the domestic market is not competitive in view of improving hygienic problems. However, international trading has been facing a serious challenge in Bangladesh as with other Asian countries. Infrastructural facilities, especially fish landing centers and wholesale and retail markets were inadequate and unhygienic, often posing serious threats to public 
health. Quality assurance programs in the country were reported to be inadequate to cope with the developments in the industry and the consumer requirements in the major seafood markets of the world (Hussain, 1994). According to Krishnaiah (2011), the fish markets were commonly filthy and unhygienic. The fish markets are often characterized by wet and slimy flooring, foul smell, deposits of fish wastages, improper drainage, presence of flies, dogs etc. High levels of noise and cacophony are symbolic of a fish market.

Public health is the science and art of preventing disease, prolonging life and promoting health through the organized efforts and informed choices of society, organizations, public and private communities and individuals. It is concerned with threats to health based on population health analysis. Environmental health, community health, behavioral health, health economics, public policy, insurance, medicine and occupational health are other important subfields of market system (Cuter and Miller, 2005). Hygiene is a set of practices performed for the preservation of health. While in modern medical sciences, there is a set of standards of hygiene recommended for different situations, what is considered hygienic or not can vary between different cultures, genders and etarian groups. Some regular hygienic practices may be considered good habits by a society while the neglect of hygiene can be considered disgusting, disrespectful or even threatening (Aiello et al., 2008). Health care services in Bangladesh arenot adequate enough to provide treatment facilities of the whole population. Moreover, poverty, illiteracy and lack of health awareness cause miserable sufferings and premature death of the people. Communicable diseases are still the major diseases in Bangladesh. The mortality and morbidity among the general mass due to contagious diseases are very high. Infectious diseases like cholera, typhoid and parasitic diseases like malaria, filariasis, and worm infestations are responsible for major morbidity (Nickson et al., 1998). Compared to the general public health situation in terms of sanitation, the supply of drinking water has been improved a lot in Bangladesh. However, the existing situation of public health of fish market stakeholders, particularly of retailers has not been developed yet. Considering above facts, the present study was carried out to understand various issues of public health being faced by the fish retailers and to assess the potential measures to be taken to develop public health situation of fish retailers in selected areas of Bangladesh.

\section{Materials and Methods}

The study was based on market survey obtaining information through a sample survey of the fish retailers. The survey was done in two fish retail markets located in the south-central region of Barisal and Rajbari Districts viz. Barisal Sadar and Rajbari Sadar markets. The south-central region is very important due to the availability of fish and a large number of fish retailers are engaged in fish marketing system. For this reason, two south-central districts of Bangladesh were selected for the research, which have been shown in Map 1 using GIS.

A total of 30 fish retailers were selected for questionnaire interviews in two different markets (Barisal Sadar $=20$ retailers; and Rajbari Sadar $=10$ retailers). To collect relevant data the interview technique i.e., primary data were collected directly from the fish retailers by the first author himself using structured questionnaire and Participatory rural appraisal (PRA) tools. In order to get a complete picture of the present status of public health and hygiene and to fulfill the objectives of the study, the questionnaire was pre-tested before survey with the retailers. Several visits were made to the study area to collect data and related information relating to the objectives of the study. After each visit, the collected data were checked for accuracy and clarity. For the study, a combination of questionnaire interviews, PRA such as focus group discussion (FGD) with key informants was used for data collection. The diseases found in the retailers were identified properly with the help of a local MBBS doctor and accordingly, disease occurrences were recorded during questionnaire testing. A simple random sampling method was followed for selection of 30 fish retailers of the south-central region in Bangladesh. In this study, FGD was used to get an overview of particular issues such as health problem, sanitation and hygiene condition etc. A total of five FGDs sessions were conducted in the fish market where each group of FGD was of 4 to 6 fish retailers. The collected data were summarized and processed for analysis. Tabular technique was applied for the analysis of data by using simple statistical tools like averages and percentages. For data processing and analysis purpose, MS Excel and MS word were used. Tables, pie-charts and bar diagrams have been used to perform descriptive statistical analysis of data. 




Map 1. Map of Bangladesh showing south-central districts of Rajbari and Barisal.

\section{Results and Discussion}

\section{Socio-economic status of the fish retailers}

Business or any entrepreneurship requires energy and the courage to take risks. The age distribution of retailers has an important influence on labour, and also on the retailers' perceptions of the future (Chang, 1994; Mandima, 1995). Fish retailing was widely accepted as an important source of income in the study areas. According to survey, about 33\% of fish retailers were in 15 to 30 years old. Sixty percent of the fish retailers were 31 to 50 years old indicating the age range of primary activity of human beings. Seven percent of farmers were 50 to 65 years of age (Table 1). As the majority of the retailers were of middle age group, therefore intervention of training, extension and spread of knowledge would be quite effective (Bhaumic et al., 1994) to build awareness in hygiene of fish retail markets. Education is an important factor in changing the attitudes and motivation of the human being. Literacy status plays a vital role in an efficient participation and operational skill in all income generating activities. Education of fish retailers was assumed to expecthelps themselves to have better access to the relevant technical information. In this study, fish retailers were categorized into three categories on the basis of level of education which has similarity with the findings of (Zaman et al., 2006). About $13 \%$ of the fish retailers had no education, $60 \%$ had primary level and $27 \%$ had secondary level of education (Table 1 ). As majority of the retailers educated although up to primary level, this has potential to make them further educated in hygiene 
maintenance in the fish markets. The majority of the people of the rural area adopt agriculture as their main occupation. Most of the fish retailers in the study area, whose main source of income and livelihood were either fish selling or agriculture (Haque et al., 2014). However, fish selling was the primary occupation of the retailers, and agriculture, fishing, sewing, service and business were their secondary occupation in the study area. It was observed that about $73 \%$ of fish retailers had primary occupation of fish selling (Table 1). The fish retailers bought fish from wholesale centers of higher secondary and secondary markets. About $70 \%$ of fish retailers were permanent and rest of them was migratory who came from other localities (Table 1). They sold fish directly to consumers through fixed stalls. On the fish market, women were found involved to sell fish and, in other important activities such as cleaning, ice processing etc. According to survey, about $20 \%$ of women were found engaged to sell fish in a fish market (Table 1).

Table 1. Socio-economic status of the fish retailers

\begin{tabular}{|c|c|c|}
\hline Characteristics & Number of fish retailers $(\mathrm{N}=30)$ & Percent (\%) of the total $(\mathrm{N}=30)$ \\
\hline $\begin{aligned} \text { Age } & \\
\text { - } & 15-30 \text { (Young age) } \\
\text { - } & 31-50 \text { (Middle age) } \\
\text { - } & 51-65 \text { (Old age) }\end{aligned}$ & $\begin{array}{l}10 \\
18 \\
2\end{array}$ & $\begin{array}{c}33 \\
60 \\
7\end{array}$ \\
\hline $\begin{aligned} & \text { Education } \\
&$\[ \quad \text { Illiterate } \]$ \\
&-\quad \text { Primary level } \\
& \text { - } \text { Secondary level } \\
&\end{aligned}$ & $\begin{array}{c}4 \\
18 \\
8\end{array}$ & $\begin{array}{l}13 \\
60 \\
27\end{array}$ \\
\hline $\begin{array}{c}\text { Occupation } \\
\qquad \quad \text { Primary (Fish retailing) } \\
\qquad \quad \text { Secondary (Others) }\end{array}$ & $\begin{array}{c}22 \\
8\end{array}$ & $\begin{array}{l}73 \\
27 \\
\end{array}$ \\
\hline $\begin{array}{cl}\text { Locale } & \\
- & \text { Locally origin } \\
\text { - } & \text { Migrated from outside }\end{array}$ & $\begin{array}{c}21 \\
9\end{array}$ & $\begin{array}{l}70 \\
30\end{array}$ \\
\hline $\begin{aligned} \text { Gender } & \\
& \text { Male } \\
& \text { - Female }\end{aligned}$ & $\begin{array}{c}24 \\
6\end{array}$ & $\begin{array}{l}80 \\
20\end{array}$ \\
\hline
\end{tabular}

\section{Health problem}

The health condition is the reflection of the livelihood status of the community. Several health problemswere found with the fish retailers in the fish market. It was found that, the fish retailers were commonly infected by a number of diseases such as common cold (cough, coryza), diarrhea, lesion (lesion on hands, lesion between fingers, lesion between toes etc.) and some other disease (Table 2). Transmission of these diseases was very common in clustered communities with little immunity and poor hygiene. Such infections were brought to home by the infected person to other members of the family. Thus the ultimate result of infection was likely to be transferred into the contagious diseases to the consumers and their other family members.

Table 2. Major diseases affected by the fish retailers in the market

\begin{tabular}{|l|c|c|}
\hline Name of disease & $\begin{array}{c}\text { Number of fish retailers } \\
\text { affected (N =30) }\end{array}$ & $\begin{array}{c}\text { Percent (\%) of the total fish } \\
\text { retailers affected (N =30) }\end{array}$ \\
\hline Common cold & 3 & 10 \\
\hline Cough & 4 & 13 \\
\hline Coryza & 3 & 10 \\
\hline Diarrhoea & & 57 \\
\hline Lesions on different organs & 17 & 33 \\
\hline Lesion on hands & 10 & 7 \\
\hline Lesion between fingers & 2 & 23 \\
\hline Lesion on the tip ofthe fingers & 7 & 13 \\
\hline Lesion between toes & 4 & 10 \\
\hline Lesion on the nail and tip of the toes & 3 & \\
\hline Skin disease on legs & & \\
\hline
\end{tabular}


Public health plays an important role in disease prevention efforts in both the developing and developed countries, through local health systems and the interventions of non-governmental organizations.

\section{Common cold disease}

The common cold (also known as nasopharyngitis, acute coryza, or simply a cold) is a viral infectious disease of the upper respiratory tract which primarily affects the nose.

Cough: Due to using water, some fish retailers were affected by the common cold disease which was mainly cough. It was observed that about $10 \%$ of fish retailers were affected by cough (Table 2). A cough is a sudden and often repetitively occurring reflex which helps to clear the large breathing passages from secretions, irritants, foreign particles and microbes. Various virus and bacteria are responsible for cough which is transmissiblefrom fish and water. From the FGD, it was known that the melting ice into water was very cold and sometimes it created cough to the retailers.

Coryza: This was another important common cold disease affected $13 \%$ of the fish retailers under the study (Table 2). Coryza is irritation and inflammation of the mucous membrane inside the nose. It is commonly caused by a viral or bacterial infection, including the common cold, which is caused by Rhinoviruses, Coronaviruses etc., or bacterial sinositis, which is commonly caused byHaemophilus paragallinarum,Streptococcus pneumonia and some other bacteria (Bragg et al., 1997). Due to unconsciousness, sometimes it creates serious problem as pneumonia.

\section{Diarrhoea}

It is a common cause of death in developing countries and the second most common cause of infant deaths worldwide (UNICEF/WHO, 2009). The loss of fluids due to diarrhoea can cause dehydration and electrolyte disturbances such as sodium, potassium, calcium, etc. deficiencies or other salt imbalances. Diarrhoea was reported to be very common disease of fish retailers under this study. According to the survey, about $10 \%$ of fish retailers were affected by diarrhea in a calendar year (Table 2 ). This was because the majority of fish retailers did not wash their hands properly, sometime they washed their hands only with water without soap. Diarrhoea is more prevalent in the developing world due to lack of safe drinking water, sanitation and hygiene, as well as poor health and nutritional status (UNICEF/WHO, 2009).There are many causes of infectious diarrhoea, which include virus, bacteria and parasites. Retailers' hands were observed to be dirty with clay, slime etc.that was supported to bear various bacteria, virus, fungi and other protozoans which could come from fish. According to Viswanathan et al. (2009) Campylobacter spp. are the common cause of bacterial diarrhoea, but infections by Salmonella spp., Shigella spp. and some strains of Escherichia coli are also very frequent.

\section{Lesion}

A lesion is any abnormality in the tissue of an organism usually caused by diseases which was found to the retailers in various forms.

Lesion on hands: Lesion was a serious disease found to be affecting the fish retailers. About $57 \%$ of the fish retailers were found to be affected by lesion on hands (Table 2). During rainy season, it increased epidemically among the stake due to higher humidity and wet condition causing lesion in hands that was aggravated by secondary infection through fungus. In some places, hands were found to be turned into whitish color, causing further lesion.Various bacteria might have grown in that lesion which might betransmitted to other stakeholders including the customers from the fish sold.

Lesion on the tip of the fingers: Some fish retailers had this disease but this was not the major health problem for them as they perceived. In the present study, about $7 \%$ of fish retailers were affected by the disease of lesion on the tip of the fingers (Table 2). Some pathogenic bacteria might growin that place which cause enteric disease while retailers can take food, cigarettes etc. in the market.

Lesion between fingers: This is a very common disease of fish retailers caused very uncomfort to them. About $33 \%$ of fish retailers faced the disease of lesion between their fingers (Table $2 \&$ Fig. 1). The majority of fish retailers faced this disease because they always with water and it persisted between the fingers for long time. Sometimes they use mustard oil to prevent this disease. The disease spreaded due to the secondary infection caused by the fungus. 

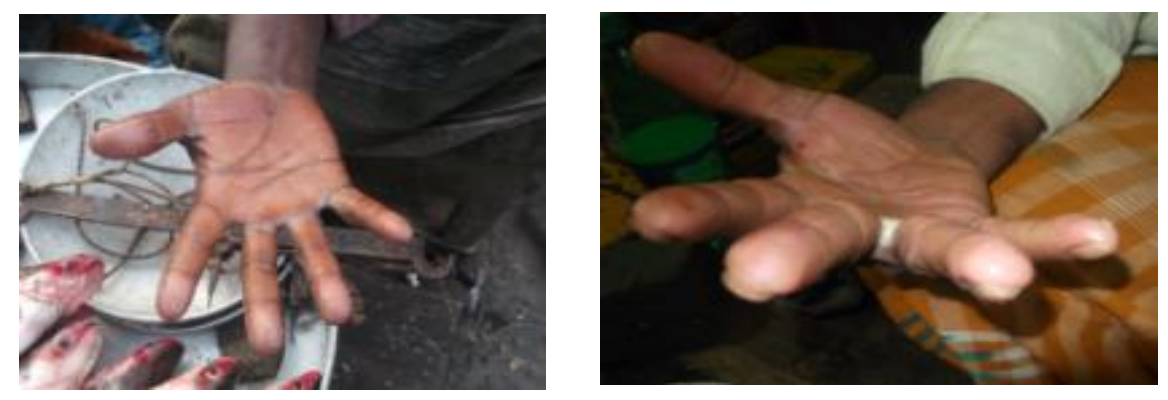

Fig. 1. Photograph showing lesion between fingers of fish retailer

Lesion between toes: The majority fish markets infrastructure and floor were found dirty. According to survey, about $23 \%$ of the fish retailers faced the disease of lesion between their toes (Table 2). The washing and cleaning spaces to sell fish, and disposal of wastes and fish residues did not meet hygienically acceptable standards. The fish washed water and the melting ice water were drained out above the platform. As a result, the fish retailers faced the disease of lesion between toes.

Lesion on the nail and tip of toes: Some fish retailers got the disease of lesion on their toes. In this study, about $13 \%$ of fish retailers faced the disease of lesion on the nail and tip of toes (Table 2).It was very common for fish retailers because the water bearing bacteria caused the disease. Sometimes fungus attacked the injured areas causing serious health problems.

Skin disease on legs: The fish retailers of the studied markets got diseases in their legs. It was observed that about $10 \%$ of fish retailers were affected by skin disease in their legs (Table 2). Due to wet condition, this disease occurred and there the secondary infection caused by fungus. The skin of legs was observed damage which has been reported to turn into whitish and blackish color.

\section{Hand washing (Hygiene maintenance)}

Hand washing can prevent diarrheal disease (which can include shigellosis, typhoid and cholera), acute respiratory infections, helminth infections and many other infectiousdiseases.

Hand washing after urination: The fish retailers were found to be relaxed in washing handsfollowingurination which wasconsidered as aserious bad habit. It was found that more than $75 \%$ of fish retailers did not wash hands after urination. As most of the male fish retailers did not wash their hands however, female fish retailers washed their hands in that case (Table 3). In terms of sex category of respondents, all the female retailers washed their hands after urination, whereas about $95 \%$ of the male respondents did not.

Table 3. Hand washing by the respondents by sex after urination

\begin{tabular}{|l|c|c|}
\hline Responses & \multicolumn{2}{|c|}{ Sex category (\%) } \\
\cline { 2 - 3 } & \multicolumn{2}{|c|}{ Memale } \\
\hline Hand washed & $100(6)$ & $4(1)$ \\
\hline Not washed & & $96(23)$ \\
\hline Total & $\mathbf{1 0 0 ( 6 )}$ & $\mathbf{1 0 0 ( 2 4 )}$ \\
\hline
\end{tabular}

Hand washing after toilet use: Hand washing with soap is very much important after toilet use because soap wash is the most effective and inexpensive way to prevent diarrhoeal diseases. Hands often act as vectors causing disease-causing pathogens from person to person, either through direct contact or indirectly via surfaces (Curtis and Cairncross, 2003). Washing hands with water alone is significantly less effective than washing hands with soap in terms of removing germs. In this case, all fish retailers washed their hands with water after toilet use but most of the time they did not use soap.

\section{Washing of utensils and platform}

In fish market, utensils and platform washing is very much important for maintenance of hygiene and preventing microbial growth. 
Source of washing water: The fish retailers used washing water which was taken from adjacent river and tubewell. In the study sites, about 57 and $43 \%$ of fish retailers used river water and tubewell water for washing, respectively (Fig. 2). In Barisal, the fish market was situated near the river, hence fish retailers used river water for washing. In Rajbari, the fish markets were placed in main town and the retailers used to use tubewell water for washing fish and their platform.

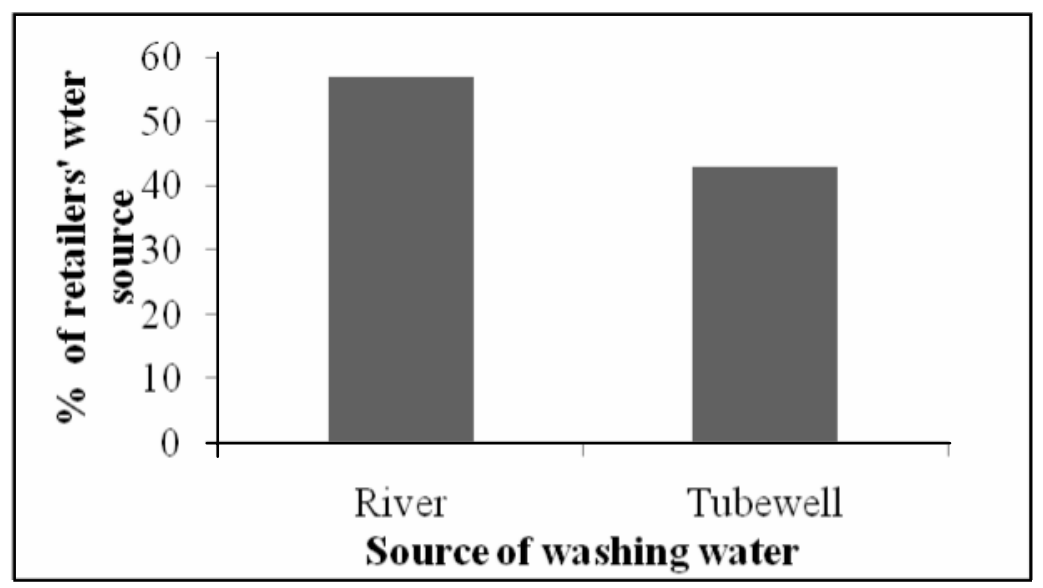

Fig. 2. The source of water used by percent of retailers

Washing frequency: Some fish retailers washed their utensils and platform daily but some others did twice a daily. It was found that about $70 \%$ of the retailers washed their selling utensils (e.g. silver pot, bowl, dalaetc.) and platform once a day and 30\% of them washed twice (Fig. 3). In this regard, the permanent fish retailers washed twice but temporary retailers washed once a day.



Fig. 3. Percent of retailers washed their fish selling utensils and platform

The facilities of fish markets were minimal, with poor hygiene and sanitation. In general, conditions of retail markets were far from satisfactory level with regards to stalls, spacing, sanitation, drainage and management which were generally perceived as ill-managed and unhygienic (Ahmed and Ahmed, 2009). There was no proper handling, washing, cleaning, icing or re-icing of the fish in the market studied. For this reason, good personal hygiene is therefore essential for the safe handling of fish. All surfaces, equipment and utensils that came into contact with fish should be cleaned and sanitized at least on a daily basis. In this study, it is clear that the hygiene and sanitation conditions should be improved in fish market by the government and non-government agencies so that the fish retailers do not need to spend additional money from their poor income to maintain their public health condition.

\section{Conclusion}

Bangladesh is a country with hundreds of rivers and ponds and is notable for being a fish-loving nation, acquiring the name "Machh-e Bhat-e Bangali" which means, "Bengali by fish and rice". Fish fauna in Bangladesh are diversed; there are about 795 native species of fish and shrimp in the fresh and marine 
waters of Bangladesh and 12 fish were introduced (Shah, 2003).Fish are the sources of income for all types of fish traders who involved in fish marketing system. Moreover, a large number of people are involved in the production and marketing of fish that made the markets very unhygienic.

To improve and develop the marketing channel, physical marketing facilities should be improved to make the whole marketing system hygienic. Proper hygiene has to be maintained in the fish handling areas for prevention of contamination and loss of quality of fish. Hygienic measures help in preventing or reducing fish spoilage, contamination and microbial growth. The Department of Public Health under the ministry of Local Government and Rural Development (LGRD) should take quick and proper action for maintaining the sanitation system and to improve the hygienic condition of retail fish market.

\section{Acknowledgments}

The authors are thankful to the fish retailers in Rajbari and Barisal under the south-central Bangladesh who participated and helped the research work. Moreover, Mr. Mokhlesur Rahman, Medical Officer (MBBS), Barisal Sadar Hospital to assist this study for identification of the diseases.

\section{References}

Ahmed, N. and Ahmed, F. 2009. Development of Tilapia Marketing Systems in Bangladesh: Potential for Food Supply. Department of Fisheries Management, Bangladesh Agricultural University, Mymensingh, Bangladesh. 21pp.

Aiello, A.E., Coulborn, R.M., Perez, V. and Larson, E.L. 2008. Effect of hand hygiene on infectious disease risk in the community setting: a meta-analysis. American Journal of Public health, 98: 1372-81.

Bhaumik, U. and Saha, S.K. 1994. Perspective on socio-economic status of the fishermen engaged in fishing in the estuaries of Sundarbans. Environmental Ecology, 12(1): 181-185.

Bragg, R.R., Greyling, J.M. and Verschoor J.A. 1997. Isolation and identification of NAD-independent bacteria from chickens with symptoms of infectious coryza. Avian Pathol, 26: 595-606.

Chang, K.C. 1994. Labour absorption in fisheries: Inevitable trends and prospects in employmentcreation. In: Socioeconomic Issues in Coastal Fisheries Management, Proceedings of the Indo-Pacific Fishery Commission Symposium, Bangkok, Thailand. 8: $49-63$.

Curtis, V. and Cairncross, S. 2003. Effects of washing hands with soap on diarrhea risk in the community: a systematic review. Infectious disease, 3: 275.

Cuter, D. and Miller, G. 2005. "The Role of Public Health Improvements in Health Advances: The Twentieth Century United States". Demography, 42(1): 1-22.

DoF. 2014. Sankalan, Matsha Saptaho, Department of Fisheries (DoF), Fisheries and Livestock Ministry, Dhaka, Bangladesh. 128pp.

Hussain, M.S. 1994. Status of backyard pond utilization in some selected areas of Bangladesh. Bangladesh Journal of Fisheries, 22(1): 113-118.

Krishnaiah, P. 2011. Management and Maintenance of Hygienic Fish Market. Department of Animal Husbandry, Dairying \& Fisheries, Ministry of Agriculture, Government of India. 6pp.

Mandima, J.J. 1995. Socioeconomic factors that influence the adoption of small-scale rural prawn farming at household level in Zimbabwe. NAGA, ICLARM Quarterly,18(2): 25-29.

Haque, M.M., Little, D.C., Barman, B.K., Wahab, M.A. and Telfer T.C. 2014. Impacts of decentralized fish fingerling production in irrigated rice fields in Northwest Bangladesh, Aquaculture Research, 45(4):655-674.

Nickson, R., McArthur, J., Burgess, W., Ahmed. K.M., Ravenscroft, P. and Rahman, M. 1998. "Arsenic poisoning of Bangladesh groundwater". Nature, 395 (6700): 338.

Rounak, A. and Rahman, M.A. 2013. Transboundary river water for Ganges and Teesta rivers in Bangladesh: An assessment. Global Science and Technology, 1: 100-111.

Shah, M.S. 2003. Human resource development activities in fisheries sector. In: Fish Fortnight Compendium 2003. Department of Fisheries, Ministry of Fisheries and Livestock, Bangladesh. Dhaka, Bangladesh. 57-59pp.

UNICEF/WHO. 2009. Diarrhoea: Why children are still dying and what can be done: UNICEF/WHO Joint Statement.

Viswanathan, V.K., Hodges, K. and Hecht, G. 2009. "Enteric infection meets intestinal function: how bacterial pathogens cause diarrhoea". Nature Reviews Microbiology,7 (2): 110-9.

Zaman, T., Jeweland, M.A.S., Bhuiyan, A.S. 2006. Present status of pond fishery resources and livelihood of the fish farmers of Mohanpur Upazila in Rajshahi District. University Journal of Zoology, Rajshahi University, 25: 31-35. 